\title{
Cataloging and Classification Practices
} in Community College Libraries

\begin{abstract}
Results of a questionnaire survey sent to a sample of community college libraries in the United States indicate that as these libraries enter the 1980s their collections are still traditionally organized. Although audiovisual materials are now cataloged and classified, there is little agreement as to how they should be organized; and most audiovisual materials are still housed in closed-access areas. Change to AACR2 seems to be accepted, but librarians are still undecided about participating in computerized cataloging networks.
\end{abstract}

$\mathbf{T}_{\mathrm{w}}$ WO RECENT STUDIES have shown that the majority of community college libraries are now using the Library of Congress classification system for the organization of printed materials. ${ }^{1}$ This is a marked increase from the results reported in earlier studies by Rowland and Taylor. ${ }^{2}$ The dates of these studies indicated the need for additional research, not only on the cataloging and classification of books but also on the classification of pamphlets, government documents, periodicals, microforms, and audiovisual materials in community college libraries. How are these materials cataloged and classified? Is there an indication that audiovisual materials are completely cataloged and classified in community college libraries? Is color banding of catalog cards for audiovisual materials still being done? How are audiovisual materials shelved? In light of the emphasis on the integration of all materials into learning resource centers of community colleges, are audiovisual materials being intershelved with printed materials? What use is being made of computerized cataloging networks? What is the composition of technical service staffs? How much original cataloging is done?

These problems prompted the develop-

Doris Cruger Dale is a professor, Department of Curriculum, Instruction and Media, Southern Illinois University, Carbondale. ment of a questionnaire designed to elicit answers to several research questions. The questionnaire was developed and criticized by two community college librarians, one from Illinois and one from New York. A pilot study was completed by sending the questionnaire to ten librarians in community college libraries that this author had visited on sabbatical leave in 1975-76. Based on criticisms and suggestions from nine of these librarians, the questionnaire was revised and then sent to a random sample of 100 community college libraries in the United States.

Prior to sending the questionnaires out, this research proposal was submitted to the Carbondale Committee for Research Involving Human Subjects. The committee found the subjects to be not at risk and approved the research proposal on November 16, 1978.

The sample of 100 libraries was randomly selected from the 1978 Community, Junior, and Technical College Directory published by the American Association of Community and Junior Colleges. Membership in that organization is not a criterion for inclusion of the names of two-year colleges. The Directory includes all institutions that are community-based community, junior, and technical colleges. Institutions are nonprofit, are organized on a two-year basis, have regional accreditation and/or state recognition, and offer two-year associate degree programs. 
Proprietary institutions are not included. Individual campuses are listed but not community centers. A total of 1,235 colleges are included of which 1,215 are in the fifty states and the District of Columbia. The total population size for this study is therefore 1,215. The sample size of 100 represented 8.23 percent of the total population. ${ }^{3}$

Because of a long-standing interest in community college libraries, each college in the sample was sent, in addition to the questionnaire, an information sheet that included data from the 1978 Directory for revision and correction, a request for the name of the person to whom future questionnaires could be sent, and a question as to whether the institution would be willing to pay the postage on return questionnaires.

In the cover letter, it was explained that this would be the first questionnaire in a longitudinal study of community college libraries, and that in the future the college might expect to receive additional questionnaires (but no more than one a year) from doctoral students or from this researcher. Participation in the project was requested and if the library was willing, the following primary documents were solicited: college catalog, campus map, a sample copy of the college newspaper, the library handbook, a recent library annual report, the library organization chart, a sample library budget, the library floor plan, a sample copy of the library newsletter, the materials selection policy, a periodical list, and an audiovisual catalog. Librarians were informed that they could withdraw from participation at any time.

The questionnaire was divided into six sections: cataloging and classification of printed materials, cataloging and classification of audiovisual materials, the catalog, shelving of audiovisual materials, computerized cataloging networks, and cataloging and classification staff. There were thirty-three questions on four pages. The questionnaire was mailed on April 2, 1979. By June 7, fifty-two questionnaires had been returned. Two of those returned were not completed. Two of the libraries were deleted from the sample population; one college was served by a local public library and one by the university library in the same city. There were forty-eight usable questionnaires, 48.98 percent of the sample population of ninety-eight. Forty-six of the persons completing the questionnaires indicated that they would be willing to participate in further studies. Questionnaires were returned from every regional division in the United States with ten returns from the South Atlantic states and ten from the Pacific states. (See table 1.)

\section{TABLE 1}

USABLE QUESTIONNAIRES BY DINTSION IN THE U.S.

\begin{tabular}{lrcc}
\hline \hline $\begin{array}{l}\text { Regional } \\
\text { Divisions* }\end{array}$ & $\begin{array}{c}\text { Number } \\
\text { of } \\
\text { Colleges }\end{array}$ & $\begin{array}{c}\text { Usable } \\
\text { Question- } \\
\text { naires }\end{array}$ & Percent \\
\hline New England & 83 & 1 & 1.20 \\
Middle Atlantic & 108 & 2 & 1.85 \\
East North Central & 220 & 5 & 2.27 \\
West North Central & 123 & 9 & 7.32 \\
South Atlantic & 234 & 10 & 4.27 \\
East South Central & 100 & 5 & 5.00 \\
West South Central & 107 & 5 & 4.67 \\
Mountain & 69 & 1 & 1.45 \\
Pacific & 171 & 10 & 5.85 \\
$\quad$ Total & 1,215 & 48 & 3.95 \\
\hline
\end{tabular}

*U.S. Census Bureau divisions as reported in "Population of the U.S. 1960-1970" in The World Almanac \& Book of Facts 19S0). p. 191 .

Although thirteen libraries have switched from the Dewey Decimal Classification (DDC) to the Library of Congress Classification (LCC) since 1965, the number of twoyear college libraries using LCC for books is not greater than the percentage reported in the Matthews study of 1972. In fact it is somewhat less. This study showed 52.08 percent using LCC for books, while the Matthews study reported 56.4 percent using LCC. DDC is favored for audiovisual materials by thirteen libraries, or 25 percent, but a wider variety of classifications is used for audiovisual materials, and sometimes a library uses more than one classification system for these materials. Eleven libraries use LCC with one of these using a modified LCC; ten libraries use an accession number and fourteen libraries use a format designation and accession number for audiovisual materials. One library assigns a course number to audiovisual materials, as evidently all audiovisual materials are used by students for classroom assignments. One library developed its own classification system for audiovisual materials, another library uses the ANSCR (Alpha-Numeric System for Classification of Recordings) for sound recordings, and one library reported that all audiovisual 
materials were kept in the department. (See table 2.)

Of the thirteen libraries switching to LCC, six started this reclassification between 1965 and 1969, four began reclassifying between 1970 and 1974, and three did not indicate when reclassification was begun. Eleven libraries have completed reclassification: three in the same year that it was begun, four within one year, one in two years, and another in four years. Two did not indicate how long the reclassification took, and two libraries are maintaining both DDC and LCC as the reclassification project continues.

Of the twenty-five libraries using LCC, sixteen are using PZ3 and 4 for fiction in English. One library uses these numbers only for authors who do not have specific numbers in the literature classes, and another library is shifting its materials out of PZ3 and 4. Nine libraries are not using PZ3 and 4. One library classifies fiction in hardback copies, but assigns the letter $F$ to paperbacks.

Fiction and biography receive special classification treatment in public libraries. This is also true of fiction and biography in two-year college libraries. Although twenty-six libraries classify fiction in DDC or LCC, thirteen libraries simply assign the letters $F$ or FIC to fiction; eight libraries use the author's last name to arrange fiction; and one library uses a Cutter number to arrange fiction.

Many libraries treat biography in more than one way. Thirty libraries arrange indi- vidual biographies in classified order by subject, ten libraries use 92 , one library uses 921 , seven libraries use the class numbers 920.1928 , and five libraries assign the letter $B$ to biography.

The Library of Congress subject headings are overwhelmingly favored for both book and audiovisual materials with one library using both lists; forty-three libraries use LC subject headings for books and forty-one use LC subject headings for audiovisual materials. (See table 3.)

Only for periodicals was there total agreement on arrangement. All forty-eight libraries in the sample arranged periodicals alphasetically by title. Microforms, government documents, and pamphlets were organized in a variety of ways. In forty-five libraries, microforms were arranged in special cabinets or drawers by title or author; one of these libraries used an accession number for arrangement. Several libraries used more than one arrangement for microforms. Six libraries intershelved their microforms; the majority of these libraries were intershelving periodicals on microfilm with their bound periodicals. One library arranged microforms in a special location by call number. Government documents were cataloged and classified in the same way as books, pamphlets, and periodicals in forty-one libraries; five libraries organized their government documents by the Superintendent of Documents classification system. One library used both of these meth-

TABLE 2

Classification Systems for BoOKS and At d)IOUISL al Materials

\begin{tabular}{|c|c|c|c|c|}
\hline \multirow[b]{2}{*}{ Classification } & \multicolumn{2}{|c|}{ Beosss } & \multicolumn{2}{|c|}{ Audion isual Naterials } \\
\hline & Number & Pereent & Number & Percent \\
\hline DDC & 23 & 47.92 & 13 & 25.00 \\
\hline LCC & 25 & 52.08 & 11 & 21.15 \\
\hline Accession number & & & 10 & 19.23 \\
\hline Format and & & & & \\
\hline accession number & & & 14 & 26.92 \\
\hline Other & & & 4 & 7.69 \\
\hline Total & 48 & 100.00 & 52 & 99.99 \\
\hline
\end{tabular}

TABLE 3

Subject HeAding Lists for Books and Aud)IOTSUal Materials

\begin{tabular}{lccccc}
\hline \hline Subject Heading List & Number & Books & Pereent & Numberionistal Naterials \\
Sears & 6 & 12.24 & 6 & 12.24 \\
LC & 43 & 87.76 & 41 & 83.67 \\
Other & & & 2 & 4.08 \\
$\quad$ Total & 49 & 100.00 & 49 & 99.99 \\
\hline
\end{tabular}


ods. Two libraries did not respond to this question, and one library reported that it did not receive any government publications.

There was more variety in the organization of pamphlets. Career pamphlets were arranged in vertical files by name of occupation in seventeen libraries, in boxes on book shelves by name of occupation in two libraries, by SRA (Science Research Associates) numbers in two libraries, by DOT (Dictionary of Occupational Titles) numbers in one library, and in binders by call number in one library. Two libraries did not respond to this question, and twenty-three libraries reported that the career pamphlets were in a separate career-counseling center in the college. Other pamphlets were arranged in alphabetical order using LC subject headings in thirty-one libraries and using Sears subject headings in five libraries. Many libraries used more than one system. Five libraries used the Readers' Guide to Periodical Literature for pamphlet subject headings; and one library used Miriam Ball's Subject Headings for the Information File (8th ed.; New York: H. W. Wilson, 1956). Two librarians did not respond to this question, and two librarians reported that they did not maintain a vertical file of pamphlets. Two librarians developed their own subject headings for pamphlets, one library used a numerical arrangement, one put them in boxes on shelves, and one cataloged them. If librarians used a standardized list of subject headings for pamphlets, they often added local subject headings on demand.

Both AACR1 and AACR2 were used as cataloging codes for books and audiovisual materials. A surprising number of libraries (sixteen) had already adopted AACR2 for books. (See table 4.)

Some libraries used more than one cataloging code for audiovisual materials. Librarians were asked whether they planned to switch to
AACR2; nine said yes, five said no, fifteen were undecided. Three did not answer this question, and the sixteen previously mentioned were already using AACR2. The four "other" answers to the question regarding catalog codes for audiovisual materials included one library that used Nonbook Materials by Jean Weihs (2d ed.; Ottawa: Canadian Library Association, 1979), one library that did not catalog those materials, one that reported that all audiovisual materials were kept in the subject department, and one library that simply checked "other" without specifying what arrangement was used.

Two libraries reported both a book catalog and a card catalog, but most libraries (fortysix) still have a card catalog; three have a book catalog, and one reported having a COM catalog. Of the forty-eight libraries, twentyone arrange catalog entries in dictionary order, seventeen have a divided catalog (sixteen divide their entries into author/title and subject order; and one library uses author and title/subject arrangement), nine libraries use a three-way divided catalog, and one librarian checked "other" and indicated that arrangement was by DDC.

Cataloging of audiovisual materials does not approach the same consistency of arrangement of entries as the cataloging of book materials. Many libraries use more than one arrangement for their audiovisual materials, but twenty-four libraries do full cataloging with data interfiled in the central catalog; eight libraries do full cataloging but file the audiovisual entries in a separate catalog near the central catalog; one library does full cataloging and files the entries in separate drawers of the central catalog; six libraries do full cataloging but file the entries in a separate catalog in the audiovisual center; and nine libraries do full cataloging and file entries in both the central catalog and in a separate

TABLE 4

Catalog Codes Used for Books and Audidisul Materials

\begin{tabular}{|c|c|c|c|c|}
\hline \multirow[b]{2}{*}{ Catalog Code } & \multicolumn{2}{|c|}{ Books } & \multicolumn{2}{|c|}{ Auclionisual Naterials } \\
\hline & Number & Percent & Number & Percent \\
\hline AACRI & 26 & 54.17 & 19 & 38.00 \\
\hline AACR2 & 16 & 33.33 & 14 & 28.00 \\
\hline AECT Standards, & & & & \\
\hline 4th ed., 1976 & & & 5 & 10.00 \\
\hline Other & & & 4 & 8.00 \\
\hline Not answered & 6 & 12.50 & 8 & 16.00 \\
\hline Total & 48 & 100.00 & 50 & 100.00 \\
\hline
\end{tabular}


catalog in the audiovisual center. Three libraries use computer printouts for the recording of audiovisual materials, and this allows them to send copies to departmental offices and to branch libraries. Five libraries issue a mimeographed list of audiovisual materials, and seven libraries use a printed list (sometimes this printed list is sent to faculty members only). Two libraries do not catalog audiovisual materials.

The identification of audiovisual materials in the catalog takes many forms. Again, more than one form may be used by a single library. Three designations were equally favored. Eighteen libraries use symbol designations, another eighteen use the medium designation, and eighteen libraries use a color code or color banding. Two libraries use a medium designation in the body of the card similar to, or according to, the general material designation recommended by AACR2. Two libraries reported using no designation. Of the eighteen libraries using a color code or banding, fifteen indicated the colors used, while three did not. It was difficult to bring order out of these patterns, as there seems to be no consistency as to which color code or banding is used for which medium. Six libraries used one color to designate audiovisual materials, but there was no agreement on the color-two used red, one used blue, two used green, and one used orange. One library used blue for audio materials, and green for visual materials. One library used eleven different colors; after running out of single colors, stripes were used. One library used ten colors; in addition to a two-color stripe, wide and narrow single-color stripes were used. Instead of using color banding for media designations, one library used colors to indicate subject areas in the library: red for humanities, light blue for social sciences, dark blue for business and science technology, brown for industrial technology, and green for natural sciences. The application of a color code or color banding seems fraught with difficulties, given the multiplicity of formats and subjects.

One librarian reported that all audiovisual call numbers were headed with a $W$, followed by a medium designation and the call number, such as WKT LB2735. F6. Another library used a format designation plus the year acquired and an accession number, i.e.,
FS/TC 75-167-a filmstrip with a tape cassette acquired in 1975 as the one hundred sixty-seventh filmstrip received that year.

One librarian stated: "At one time, we used color codes and abbreviations for the various forms of AV materials. We also used sequential numbering for each medium, e.g., AT10 - audiotape - tenth tape to be added to the collection. We now assign LC classification numbers and use the same color card that we use for books. We are considering going back to using color-coded cards because our students often ask for a list of audiovisual materials owned by our library. It will be easier to access this information if we used a colorcoded system."

The shelving of audiovisual materials presents many problems because of the varying sizes and shapes of these materials. Librarians do not agree on shelving patterns, and in many cases they use different patterns to shelve different types of materials. All audiovisual materials may be on closed shelves or in a closed area with the exception of sound recordings, which might be in open bins for browsing. All audiovisual materials might be intershelved with book materials with the exception of $16 \mathrm{~mm}$ films. Among the libraries that responded to this survey, thirty-nine reported that audiovisual materials were in a closed area (twenty-six on closed shelves and thirteen in closed cabinets) but in some cases this area was open to faculty members, and twenty-four reported that audiovisual materials, or at least some of them, were in an area open to faculty and students (nineteen kept these materials on open shelves and five kept them in open access cabinets or drawers). One librarian reported that these materials were kept in the subject department. Of the libraries that shelved these materials in open areas, six intershelved audiovisual materials with books, twelve separated them by format or medium, and eight separated them by classification number. One librarian did not respond. Although it seems that there are more exceptions for the shelving of audiovisual materials, it must be remembered that there are also exceptions for printed materials because periodicals, government publications, and pamphlets are shelved in special ways. The more patterns of arrangement of materials by format or by the package in which materials are organized, the more difficult it becomes 
to try to gather together all the materials that a library owns on one subject.

Librarians were asked about their participation in computerized cataloging networks. Although two librarians did not respond to this question, thirty-nine reported that they did not participate in computerized cataloging networks. Two of these libraries were using commercial processing services and two received their cataloging from a centralized technical service operation for the district. Only seven libraries were participating in computerized cataloging networks, six of them with OCLC and one with WLN (Washington Library Network). Librarians were asked if they were planning to participate in such a network; twenty-three said no, seven said yes, eight were undecided, and three did not respond.

The final section of the questionnaire included questions regarding cataloging and classification staff, numbers of materials added, and percentage of cataloging copy from original and commercial sources. Most of the forty-eight libraries responding reported that they had only one full-time professional cataloging person; nineteen libraries reported one professional, and fifteen reported one paraprofessional staff. Another twenty reported none, or less than one, professional staff, and sixteen reported none, or less than one, paraprofessional staff. Four libraries reported two professionals, and one library reported three professionals. Four did not report their professional staff. Fourteen libraries reported more than one paraprofessional staff, and three did not respond to this question. (See table 5.) Of the forty-eight libraries, twenty reported no weekly hours of student workers, nine reported one to ten hours, ten reported eleven to twenty hours, four reported twenty-one to thirty hours, and two reported forty-one to fifty hours. Three did not respond to this question.

On a monthly basis, libraries added more books than audiovisual materials to their collections. Five hundred books or fewer were added monthly by thirty-three libraries; thirty-one libraries added 100 or fewer audiovisual items. Several librarians reported that they did not keep these statistics, and five librarians did not respond to this question. (See table 6.)

More original cataloging was done for audiovisual materials than for book materials. Only three libraries reported doing 91 to 100 percent original cataloging for books while twenty libraries reported doing 91 to 100 percent original cataloging for audiovisual materials. Ten libraries reported that they did not record this data. (See table 7.) Librarians were asked if they had done any studies on cataloging costs; three said yes and forty no. Two were in the process of completing cost studies, and three did not answer this question. One librarian reported that a study had been done a number of years ago but was no longer valid.

The cataloging and classification practices of typical two-year college libraries as they entered the 1980s can be summarized as follows: book collections are classified by either the Dewey Decimal Classification system or the Library of Congress Classification system, and audiovisual materials are classified in a variety of arrangements. Library of Congress subject headings are used for both books and audiovisual materials. Periodicals are shelved in alphabetical order by title. Microforms are arranged in special cabinets or drawers by

TABLE 5

Cataloging and Classification StafF in FTE (Full-Tine Equinalent)

\begin{tabular}{|c|c|c|c|c|}
\hline \multirow[b]{2}{*}{ FTE } & \multicolumn{2}{|c|}{ Professional } & \multicolumn{2}{|c|}{ Paraprofessional } \\
\hline & $\begin{array}{c}\text { Number of } \\
\text { Libraries }\end{array}$ & Percent & $\begin{array}{l}\text { Number of } \\
\text { Liloraries }\end{array}$ & Percent \\
\hline None & 4 & 8.33 & 5 & 10.42 \\
\hline Less than 1 & 16 & 33.33 & 11 & 22.92 \\
\hline 1.00 & 19 & 39.58 & 15 & 31.25 \\
\hline 1.50 & - & - & 5 & 10.42 \\
\hline 2.00 & 4 & 8.33 & 5 & 10.42 \\
\hline 2.50 & - & - & 1 & 2.08 \\
\hline 2.75 & - & - & 1 & 2.08 \\
\hline 3.00 & 1 & 2.08 & 2 & 4.17 \\
\hline No answer & 4 & 8.33 & 3 & 6.25 \\
\hline Total & 48 & 99.98 & 48 & 100.01 \\
\hline
\end{tabular}


TABLE 6

Books and Audiovisual Materials Adjed to Collections

\begin{tabular}{|c|c|c|c|c|}
\hline \multirow[b]{2}{*}{ Number } & \multicolumn{2}{|c|}{ Beooks } & \multicolumn{2}{|c|}{ Andionistal Naterials } \\
\hline & $\begin{array}{c}\text { Number of } \\
\text { Libraries }\end{array}$ & Percent & $\begin{array}{l}\text { Niumber of } \\
\text { Libraries }\end{array}$ & Pereent \\
\hline 0 & - & - & 1 & 2.08 \\
\hline $1-50$ & 2 & 4.17 & 27 & 56.25 \\
\hline $51-100$ & 12 & 25.00 & 3 & 6.25 \\
\hline $101-150$ & 5 & 10.42 & - & - \\
\hline $151-200$ & 3 & 6.25 & - & - \\
\hline $201-250$ & 4 & 8.33 & - & - \\
\hline $251-300$ & 2 & 4.17 & - & - \\
\hline $301-350$ & - & - & - & - \\
\hline $351-400$ & 3 & 6.25 & - & - \\
\hline $401-450$ & 1 & 2.08 & - & - \\
\hline $451-500$ & 1 & 2.08 & - & - \\
\hline $500+$ & 1 & 2.08 & 1 & 2.08 \\
\hline Not recorded & 9 & 18.75 & 11 & 22.92 \\
\hline Not answered & 5 & 10.42 & 5 & 10.42 \\
\hline Total & 48 & 100.00 & 48 & 100.00 \\
\hline
\end{tabular}

title or author. Government publications are cataloged and classified in the same way as other books, pamphlets, and periodicals. Career pamphlets are housed in a separate career-counseling center. Other pamphlets are arranged in alphabetical order using $\mathrm{Li}$ brary of Congress subject headings. AACR1 is used as the cataloging code for both books and audiovisual materials, and change to AACR2 is anticipated. Libraries have a card catalog arranged either in dictionary or in divided order. Audiovisual materials are classified and cataloged in a variety of ways; call number designations for these materials are varied. Most audiovisual materials are shelved in

TABLE 7

Use of Original and Commercial Cataloging:

\begin{tabular}{|c|c|c|c|c|}
\hline \multirow[b]{2}{*}{ Percent } & \multicolumn{2}{|c|}{ Books } & \multicolumn{2}{|c|}{$\begin{array}{l}\text { Audiovisual } \\
\text { Materials }\end{array}$} \\
\hline & Orig. & $\mathrm{Cml}$. & Orig. & Cml. \\
\hline 0 & 1 & 3 & - & 18 \\
\hline $1-10$ & 15 & - & - & 4 \\
\hline $11-20$ & 5 & 1 & 2 & 1 \\
\hline $21-30$ & 4 & - & - & 1 \\
\hline $31-40$ & - & 1 & 1 & 1 \\
\hline $41-50$ & 2 & 2 & 3 & 3 \\
\hline $51-60$ & 1 & - & 1 & - \\
\hline $61-70$ & - & 1 & - & 1 \\
\hline $71-80$ & 1 & 6 & 1 & 2 \\
\hline $81-90$ & - & 9 & 3 & - \\
\hline $91-100$ & 3 & 9 & 20 & - \\
\hline \multicolumn{5}{|l|}{ Unusable } \\
\hline $\begin{array}{l}\text { or no } \\
\text { response }\end{array}$ & 6 & 6 & 7 & 7 \\
\hline \multicolumn{5}{|l|}{ Data not } \\
\hline recorded & 10 & 10 & 10 & 10 \\
\hline Total & 48 & 48 & 48 & 48 \\
\hline
\end{tabular}

closed-access areas. Libraries do not yet participate in computerized cataloging networks and either are not planning to participate or are undecided. Cataloging staffs consist of one full-time professional and one paraprofessional person or less with no student help. On a monthly basis, 500 books or fewer are added to the collection and 100 audiovisual items or fewer are added. More original cataloging is done for audiovisual materials than for books.

The data indicate that two-year college libraries are traditionally organized libraries as they enter the 1980s. Most audiovisual materials are classified and cataloged, but it seems evident that they have not been fully accepted or integrated into the book collection. With the advent of the computer age, it will be interesting to replicate this study in the year 2000 to see what impact the computer will have on these libraries.

\section{REFERENCES}

1. Elizabeth Woodfin Matthews, "Characteristics and Academic Preparation of Directors of Library-Learning Resource Centers in Selected Community Colleges" (Ph.D. dissertation, Southern Illinois Univ., Carbondale, 1972), p.129. LCC was used by 56.4 percent of the 420 libraries in this study and DDC was used by 42.9 percent. Catherine Johnson, "Classification Systems Used in Illinois Public Community College Learning Resource Centers" (M.S. research paper, Southern Illinois Univ., Carbondale, 1974), p.16. LCC was used by 70 percent of 40 community college libraries in Illinois, DDC was used by 30 percent. 
2. Arthur Ray Rowland, "Cataloging and Classification in Junior College Libraries," Library Resources \& Technical Services 7:254 (Summer 1963). Rowland reported that 96.5 percent of 315 junior college libraries were using DDC and only 3.5 percent were using LCC. Desmond Taylor, "Classification Trends in Junior College Libraries," College \& Research Libraries 29:352 (Sept. 1968). Taylor reported 77.1 percent of 690 junior college libraries using DDC and 13.3 percent using LCC. $\mathrm{He}$ also reported that 8.4 percent were changing from DDC to LCC, and 0.6 percent were planning to change.

3. Rand Corporation, A Million Random Digits with 100,000 Normal Deviates (Glencoe, Ill.: Free Pr., 1955), p.4. Reprinted in Ray L. Carpenter and Ellen Storey Vasu, Statistical Methods for Librarians (Chicago: American Library Assn., 1978), p.96-97. 